\title{
Combating corruption the soft way
}

Citation for published version (APA):

Jongen, H. J. E. M. (2017). Combating corruption the soft way: the authority of peer reviews in the global fight against graft. [Doctoral Thesis, Maastricht University]. Datawyse / Universitaire Pers Maastricht. https://doi.org/10.26481/dis.20170915hj

Document status and date:

Published: 01/01/2017

DOI:

10.26481/dis.20170915hj

Document Version:

Publisher's PDF, also known as Version of record

\section{Please check the document version of this publication:}

- A submitted manuscript is the version of the article upon submission and before peer-review. There can be important differences between the submitted version and the official published version of record.

People interested in the research are advised to contact the author for the final version of the publication, or visit the DOI to the publisher's website.

- The final author version and the galley proof are versions of the publication after peer review.

- The final published version features the final layout of the paper including the volume, issue and page numbers.

Link to publication

\footnotetext{
General rights rights.

- You may freely distribute the URL identifying the publication in the public portal. please follow below link for the End User Agreement:

www.umlib.nl/taverne-license

Take down policy

If you believe that this document breaches copyright please contact us at:

repository@maastrichtuniversity.nl

providing details and we will investigate your claim.
}

Copyright and moral rights for the publications made accessible in the public portal are retained by the authors and/or other copyright owners and it is a condition of accessing publications that users recognise and abide by the legal requirements associated with these

- Users may download and print one copy of any publication from the public portal for the purpose of private study or research.

- You may not further distribute the material or use it for any profit-making activity or commercial gain

If the publication is distributed under the terms of Article $25 \mathrm{fa}$ of the Dutch Copyright Act, indicated by the "Taverne" license above, 
Nederlandse samenvatting 

In de afgelopen twee decennia heeft een wereldwijde, normatieve verschuiving plaatsgevonden omtrent corruptie. Tot de jaren ' 90 van de vorige eeuw werd het omkopen van buitenlandse ambtenaren doorgaans beschouwd als een geaccepteerd onderdeel van internationale handel en waren steekpenningen in diverse Europese landen fiscaal aftrekbaar. In een relatief kort tijdsbestek is de algemene visie op corruptie echter aanzienlijk veranderd. Het einde van de Koude Oorlog en de aansluitende golven van democratisering en economische liberalisering luidden een nieuw tijdperk in, waarin corruptie niet langer werd geduld. Vandaag de dag wordt corruptie doorgaans beschouwd als een ernstige belemmering voor economische ontwikkeling, democratisch bestuur en effectieve armoedebestrijding.

Een manier waarop bovengenoemde normatieve verschuiving tot uiting komt is het aantal multilaterale verdragen dat tracht corruptie op internationaal niveau aan te pakken. Landen hebben zich in het algemeen bereid getoond deze verdragen te ondertekenen om zodoende hun inzet kenbaar te maken om actie te ondernemen tegen corruptie. Een handtekening alleen is echter onvoldoende om corruptie ook daadwerkelijk te bestrijden. Gebrek aan politieke wil, maar ook een tekort aan expertise of financiële middelen, gooien regelmatig roet in het eten en verhinderen de naleving van deze verdragen. Aangezien er op internationaal niveau geen toezichtsorgaan of rechterlijke macht is die landen ertoe kan dwingen zich aan hun internationale afspraken te houden, dient de vraag zich aan hoe landen toch aangezet kunnen worden om aan hun verplichtingen te voldoen.

Een mogelijk antwoord op bovenstaande vraag is: door middel van wederzijdse, interstatelijke evaluaties, in het Engels peer reviews genoemd. Deze peer reviews vormen het meest gebruikte evaluatiemechanisme op het gebied van corruptiebestrijding. Peer review berust op een systeem waarin landen elkaar beoordelen met betrekking tot de naleving en uitvoering van internationale anticorruptie verdragen. Het eindproduct van een dergelijke evaluatie is een rapport met aanbevelingen hoe het geëvalueerde land zijn functioneren kan verbeteren. Landen kunnen door middel van dit evaluatiemechanisme elkaar niet dwingen om deze aanbevelingen uit te voeren. In plaats daarvan tracht het mechanisme landen aan te sporen tot verandering door middel van groepsdruk en landen publiekelijk terecht te wijzen (naming-and-shaming) alsmede door het stimuleren van beleidsleren, het uitwisselen van ervaringen, en het opbouwen van de capaciteiten van landen om corruptie te bestrijden.

In mijn proefschrift bestudeer ik het gezag van peer reviews in de wereldwijde bestrijding van corruptie. Gezag is noodzakelijk voor deze evaluatiemechanismen om landen daadwerkelijk ertoe aan te zetten hun beloftes na te leven. Zoals eerder genoemd is het namelijk niet mogelijk landen te dwingen de wettelijk niet-bindende aanbevelingen van de evaluaties uit te voeren. Gezag is echter niet toereikend. Het is mogelijk dat landen bereid zijn de aanbevelingen van een gezaghebbend peer review op te volgen, maar in 
de praktijk door financiële of politieke omstandigheden niet in staat zijn deze ook te implementeren. Toch zullen zij eerder bereid zijn de aanbevelingen van een gezaghebbend peer review serieus in overweging te nemen.

In dit onderzoek probeer ik antwoorden te vinden op drie vragen: (1) Hoe kunnen we het gezag van een peer review mechanisme conceptualiseren en meten? (2) Hoeveel gezag hebben verschillende peer review mechanismen op het gebied van corruptiebestrijding? (3) Hoe kunnen mogelijke verschillen in het gezag van peer reviews worden verklaard? In Hoofdstuk 2 beantwoord ik het eerste aspect van de eerste vraag: hoe kunnen we het gezag van een peer review conceptualiseren? Ik laat zien dat veel academici de term 'gezag' gebruiken, maar vaak naar verschillende zaken refereren. Ik poneer dat het gezag van een beleidsinstrument zoals een peer review, het best benaderd kan worden als een sociologisch en relationeel concept. In deze benadering verwijst gezag niet naar zekere competenties of bevoegdheden die een ambtsdrager of institutie kan bezitten en ook weer kan doorgeven aan een mogelijke opvolger (zoals het gezag of de autoriteit van een President). In plaats daarvan berust gezag op een sociale relatie; gezag bestaat in zoverre dat de beoogde volgers het gezag van een persoon of institutie ook daadwerkelijk erkennen. Een voorbeeld is het gezag van een Professor, wat berust op de sociale erkenning van zijn of haar expertise in een bepaald vakgebied. Toegepast op peer reviews uit dit gezag zich op twee manieren: (1) de beoogde volgers van een peer review beschouwen het peer review als legitiem en (2) de landen die deelnemen aan het peer review conformeren zich aan de sociale normen van het mechanisme.

In Hoofdstuk 3 behandel ik vervolgens de methodologische basis van de studie. In dit hoofdstuk stel ik dat zowel kwalitatieve als kwantitatieve onderzoeksmethodes voor het verzamelen en analyseren van data noodzakelijk zijn om de drie vragen te beantwoorden. Deze data bestaan uit (1) 45 semigestructureerde interviews met diplomaten, leden van het Secretariaat van de betreffende internationale organisaties en deskundigen op het gebied van corruptiebestrijding, welke verantwoordelijk zijn voor de uitvoering van de evaluaties of hebben opgetreden als delegatielid, (2) een online vragenlijst die verstuurd is naar meer dan 500 ambtenaren en deskundigen (responspercentage van 48.8\%) en (3) een groot aantal online beleidsdocumenten, waaronder evaluatierapporten, verslagen van vergaderingen, voortgangsrapporten en synthese rapporten. In aanvulling op de discussie van de verschillende bronnen die ik geconsulteerd en geanalyseerd heb, bespreek ik in dit hoofdstuk de methode van vergelijkend casus onderzoek en onderbouw ik de keuze voor drie casussen: (1) de Werkgroep inzake Omkoping bij Internationale Zakelijke Transacties georganiseerd door de Organisatie voor Economische Samenwerking en Ontwikkeling (OESO), (2) de Groep Staten tegen Corruptie (GRECO) van de Raad van Europa en (3) het evaluatiemechanisme van het Verdrag van de Verenigde Naties tegen Corruptie (VVNC).

In Hoofdstuk 4 komt het tweede aspect van de eerste onderzoeksvraag aan bod: hoe kunnen we het gezag van een peer review empirisch meten? Dit proefschrift is niet het 
eerste onderzoek dat het concept 'gezag' benadert als een sociale relatie. Het is echter wel een van de eerste academische studies die het concept operationaliseren in meetbare componenten. Ik maak hierbij gebruik van 15 verkennende, semigestructureerde interviews alsmede verschillende inzichten verkregen uit de secundaire literatuur. Zodoende heb ik diverse maatstaven ontwikkeld van de gepercipieerde legitimiteit van een peer review: de algemene perceptie dat een peer review een gepast beleidsinstrument is (de missie van het instrument), dat betekenisvolle resultaten boekt (de capaciteiten van het instrument) en dat procedureel legitiem is (het proceduralisme van het instrument). De verkennende interviews gaven aan dat zulke percepties afhankelijk zijn van de context waarin een peer review opereert; wat als gepast en eerlijk wordt beschouwd in een specifiek peer review hoeft niet noodzakelijkerwijs ook in een andere context gewaardeerd te worden. In plaats van de legitimiteit van een peer review te meten aan de hand van externe, normatieve standaarden, bestudeer ik daarom in welke mate een peer review voldoet aan context-afhankelijke verwachtingen van zijn legitimiteit, dat wil zeggen, ik onderzoek de sociologische legitimiteit van een peer review. In aanvulling op de maatstaven die ik heb ontwikkeld om de gepercipieerde legitimiteit van een peer review te bestuderen, heb ik aan de hand van de verkennende interviews ook maatstaven ontwikkeld van de mate waarin landen zich conformeren aan de sociale normen van een peer review. Drie maatstaven heb ik vervolgens uitgekozen: het opkomstpercentage bij plenaire vergaderingen, het percentage landen dat hun evaluatierapporten vrijwillig en in zijn geheel publiceert en de mate waarin landen responsief zijn in de evaluaties en tijdig informatie aanleveren.

$\mathrm{Na}$ het ontwikkelen van maatstaven van het gezag van een peer review, heb ik deze maatstaven toegepast op de eerder genoemde drie casussen met als doel het beantwoorden van de tweede vraag: hoeveel gezag hebben verschillende peer reviews op het gebied van corruptiebestrijding? Ik laat in Hoofdstuk 5 zien dat het gezag van de drie peer reviews verschilt. Het GRECO mechanisme bezit relatief het meeste gezag. In de regel beschouwen de deelnemers aan dit peer review het mechanisme als zeer legitiem en conformeren landen zich aan de sociale normen van het mechanisme. De GRECO wordt in het algemeen zeer positief beoordeeld op vrijwel alle dimensies, sub dimensies en maatstaven van gezag, met uitzondering van het faciliteren van technische assistentie aan lidstaten om de aanbevelingen te implementeren. De sterke punten van dit mechanisme zijn de gepercipieerde nauwkeurigheid van zijn evaluatierapporten en de praktische uitvoerbaarheid van de aanbevelingen. Het mechanisme wordt ook gewaardeerd om de kwaliteit van de procedures en de correcte toepassing van deze procedures in de praktijk. Tweede in de rij van gezaghebbende peer reviews is de OESO Werkgroep. Van de drie bestudeerde casussen is de OESO Werkgroep het best in staat druk uit te oefenen op landen om de aanbevelingen te implementeren. Echter, de manier waarop deze druk wordt uitgeoefend, wordt niet altijd gewaardeerd. Relatief scoort dit mechanisme minder goed op de correcte toepassing van procedures en regels (d.w.z. de mate waarin procedures consequent worden toegepast). De kracht van dit mechanisme ligt voornamelijk 
in de resultaten dat het boekt in plaats van de manier waarop deze resultaten bereikt worden. De mate waarin landen zich conformeren aan de sociale normen van dit evaluatiemechanisme komt echter wel overeen met die van de GRECO. Tot slot is het VN mechanisme het minst gezaghebbend. Als het jongste en grootste peer review op het gebied van corruptiebestrijding moet dit mechanisme zijn plek nog vinden tussen de gevestigde instrumenten. De meningen blijken dan ook verdeeld over het doel van dit peer review (zijn missie) en hoe dit doel te bereiken (procedures). Evenzo is dit mechanisme zeer beperkt in staat druk uit te oefenen op landen om de aanbevelingen voortkomende uit de evaluaties te implementeren en conformeert een relatief groot aantal landen zich niet aan de normen van het mechanisme. Desalniettemin is het VN mechanisme relatief het best in staat technische assistentie te verlenen aan landen en ook in termen van correcte naleving van procedures doet het mechanisme het goed.

In aanvulling op bovenstaande bevindingen concludeer ik dat verschillende groepen individuen de legitimiteit van de drie peer reviews verschillend beoordelen. Dit is voornamelijk waarneembaar in het $\mathrm{VN}$ mechanisme, waar de regionale afkomst van respondenten dikwijls een statistisch significant effect heeft op hun percepties inzake de legitimiteit van het mechanisme. In de regel wijken de visies van West-Europese ambtenaren en diplomaten op de legitimiteit en gepastheid van het VN mechanisme significant af van die van hun Afrikaanse en Aziatische collega's. De West-Europese deelnemers blijken veelal sceptischer over het mechanisme dan de Aziaten en Afrikanen. Deze bevindingen onderstrepen de relevantie om gezag als een sociologisch concept te benaderen. De gradatie van het gezag van een peer review is afhankelijk van de subjectieve interpretatie van legitimiteit door de beoogde volgers van het peer review. Wat de een als zeer legitiem beschouwd, kan in de ogen van een ander minder gepast zijn.

Nadat ik in Hoofdstuk 5 heb vastgesteld dat de drie peer reviews er verschillende gradaties van gezag op nahouden, probeer ik deze verschillen in Hoofdstuk 6 te verklaren. Ik maak hiervoor gebruik van de interviews en-doch in mindere mate-de online questionnaire. Ik begin met het verkennen van de relevantie van drie verklarende factoren die zijn uiteengezet in de secundaire literatuur: (1) het aantal en de heterogeniteit van de deelnemende landen aan een peer review, (2) de samenstelling van delegaties naar een peer review (d.w.z. voornamelijk experts versus een combinatie van experts en diplomaten) en (3) de institutionele vormgeving van een peer review. Enkel gebaseerd op de literatuur is het echter onduidelijk hoe deze factoren zich verhouden tot het gezag van een peer review. Bovendien is de kans aanwezig dat andere factoren een rol spelen in de vorming van gezag, die vooralsnog niet beschreven zijn in de literatuur. Dit hoofdstuk is daarom deels van een inductieve en verkennende aard.

Mijn studie wijst uit dat de eerste verklarende factor, het aantal en de diversiteit aan landen dat deelneemt aan een peer review, van invloed is op het gezag van het instrument. Het grootste en meest heterogene peer review, namelijk dat van de VN, heeft minder gezag dan de kleinere en homogenere OESO Werkgroep en GRECO. Deze factor biedt een verklaring voor drie aspecten: (1) waarom de functies van het VN mechanisme meer 
betwist worden dan die van de twee andere peer reviews, (2) waarom de geschiktheid van de procedures van het VN mechanisme veelvuldig onderwerp zijn van discussie en (3) waarom in het VN mechanisme relatief minder landen zich conformeren aan de sociale normen van het peer review dan in de andere twee peer reviews. Interessant genoeg blijkt dat deze eerste factor zich op een andere manier verhoudt tot het gezag van een peer review dan verwacht. Drie aspecten die gelieerd zijn aan de grootte en heterogeniteit van peer review blijken van belang te zijn voor het gezag van een peer review: (1) heterogeniteit inzake de ervaringen die de lidstaten hebben met peer review als een evaluatiemechanisme, (2) heterogeniteit omtrent de beweegredenen voor landen om deel te nemen aan een peer review en (3) de exclusiviteit en het prestige van een peer review met een exclusief lidmaatschap. Mijn studie toont aan dat, anders dan verwacht, er niet sprake is van meer wederzijds vertrouwen in de kleine, homogenere peer reviews dan in het grote $\mathrm{VN}$ mechanisme.

De tweede verklarende factor is gerelateerd aan de compositie van delegaties naar een peer review. Het peer review waarbij relatief gezien de meeste diplomaten betrokken zijn, het VN mechanisme, heeft ook het minste gezag. De delegaties naar de Werkgroep inzake Omkoping en de GRECO bestaan daarentegen voornamelijk uit bureaucraten en experts op de inhoudelijke aspecten van corruptiebestrijding. Ik laat zien dat dit een verklaring biedt voor de waargenomen verschillen in druk die de OESO Werkgroep en de GRECO weten uit te oefenen op hun lidstaten in vergelijking tot het VN mechanisme. De aanwezigheid van diplomaten in het laatstgenoemde mechanisme leidt tot ongunstige omstandigheden voor lidstaten om druk uit te oefenen, deels omdat de sfeer meer politiek geladen wordt en deels omdat diplomaten vaak niet de noodzakelijke, technische achtergrond hebben om kritische, inhoudelijke vragen te stellen. Echter, de specificatie dat de evaluaties worden uitgevoerd door experts (wat het geval is voor alle drie de peer reviews) versterkt het gezag van deze mechanismen. Het verklaart waarom wederzijds vertrouwen tamelijk hoog is in de peer reviews en waarom de evaluaties als technisch en objectief worden beschouwd.

De derde verklarende factor betreft de institutionele vormgeving van een peer review, welke ook van invloed blijkt te zijn op het gezag van een peer review. Deze factor biedt een plausibele verklaring voor de volgende waargenomen verschillen in gezag tussen de drie casussen: (1) waarom de OESO Werkgroep en de GRECO relatief beter in staat zijn druk uit te oefenen dan het VN mechanisme en (2) waarom de evaluatierapporten van het $\mathrm{VN}$ mechanisme in het algemeen als minder accuraat worden beschouwd dan die van de andere peer reviews. Enkel gebaseerd op de secundaire literatuur was het echter onduidelijk welke aspecten of kenmerken van de institutionele vormgeving van een peer review van invloed zijn op gezag. In mijn studie identificeer ik vijf relevante institutionele kenmerken: (1) het bespreken van evaluatierapporten tijdens de plenaire vergaderingen, (2) de procedures voor het aannemen van evaluatierapporten (consensus versus consensus min een), (3) de verplichtingen die het mechanisme oplegt aan lidstaten (bijv. betref- 
fende het ondergaan van een landenbezoek of de publicatie van rapporten), (4) de aanwezigheid van een system voor follow-up monitoring en (5) de transparantie van plenaire vergaderingen. Interviews suggereren dat een aantal van deze kenmerken ook een rol speelt bij de consequente toepassing van procedures (het proceduralisme van een peer review). Het is echter belangrijk enige voorzichtigheid in acht te nemen met de interpretatie van de resultaten van het proceduralisme van de peer reviews.

De vierde verklarende factor, de leidende rol van diverse actoren binnen het peer review op het gebied van corruptiebestrijding (d.w.z. policy entrepreneurship), komt niet voort uit de secundaire literatuur, maar is inductief verkregen. Deze factor verheldert waarom de GRECO en het OESO mechanisme (twee mechanismen die een vergelijkbaar ledenbestand en institutionele vormgeving hebben alsmede beide voornamelijk technische experts behelzen), verschillende gradaties van gezag bezitten. Concreter genomen biedt deze factor een aanvullende verklaring waarom: (1) de druk in de OESO Werkgroep hoger is dan in de GRECO, (2) waarom de OESO Werkgroep minder goed in staat wordt geacht om de regels en procedures correct toe te passen en (3) waarom de deelnemende landen zich in gelijke mate conformeren aan de sociale normen van beide peer reviews. Ik laat zien dat in het bijzonder de leidende rol van de Verenigde Staten en voormalig voorzitter van de OESO Werkgroep, Mark Pieth, de druk substantieel hebben weten op te voeren op landen om de aanbevelingen op te volgen. De manier waarop deze druk wordt uitgevoerd wordt echter niet altijd gewaardeerd.

In Hoofdstuk 7 vat ik de belangrijkste bevindingen van mijn onderzoek samen. Ten eerste bespreek ik de implicaties van de studie voor de academische literatuur evenals de generaliseerbaarheid van mijn bevindingen voor zowel peer reviews in andere internationale organisaties en beleidsvelden als voor vergelijkbare evaluatiemechanismen. Mijn bevindingen zijn onder andere relevant voor de literatuur betreffende socialisatie in internationale organisaties en diverse stromingen binnen het institutionalisme. Ten tweede geef ik verschillende aanbevelingen voor beleidsdoeleinden. Ik richt mij hierbij specifiek op de transparantie van het VN peer review en de ontwikkeling van een followup mechanisme, aangezien deze aspecten veelvuldig werden aangekaart tijdens interviews. Zo stel ik voor dat het VN mechanisme een van de volgende opties in overweging neemt: (1) het peer review transparanter te maken voor deelnemende landen of (2) het peer review transparanter te maken voor de buitenwereld. Met betrekking tot het followup mechanisme adviseer ik een combinatie van schriftelijke en mondelinge follow-up. Voor peer reviews in het algemeen zet ik verschillende procedures uiteen die in overweging kunnen worden genomen met als doel het creëren van een peer review dat druk uitoefent op lidstaten en tevens gelijke behandeling en invloed van landen waarborgt. Ten derde reflecteer ik op de grenzen van mijn studie en bespreek ik diverse mogelijkheden voor vervolgstudies. Tot slot werp ik een blik op de toekomst voor peer review als een evaluatiemechanisme in de wereldwijde bestrijding van corruptie onder andere in overweging nemende de recente ontwikkelingen in de Verenigde Staten onder het Presidentschap van Donald Trump. 